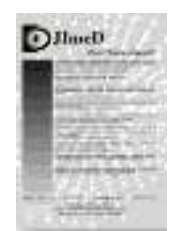

Jurnal Imejing Diagnostik (JImeD) 6 (2020) 1-6

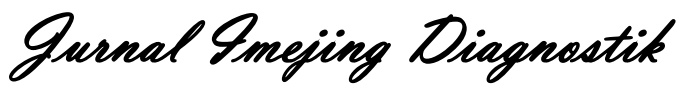

e-ISSN 2621-7457, p-ISSN 2356-301X

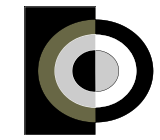

http://ejournal.poltekkes-

smg.ac.id/ojs/index.php/jimed/index

\title{
Tatalaksana Radioterapi Eksterna pada Kanker Payudara dengan Teknik Simultaneous Integrated Booster (SIB) di Unit Radioterapi Instalasi Radiologi RS Ken Saras Kabupaten Semarang
}

\author{
Ardani $^{1}$, Edy Susanto ${ }^{2}$, Nanang Sulaksono ${ }^{3}$, Sri Mulyati ${ }^{4}$ \\ ${ }^{1)}$ Rumah Sakit Paru dr. Ario Wirawan Salatiga, Indonesia \\ 2,3,4) Jurusan Teknik Radiodiagnostik dan Radioterapi, Poltekkes Kemenkes Semarang, Indonesia \\ Corresponding author: Ardani \\ Email: danitingkir@gmail.com
}

Received: January $30^{\text {th }}, 2020$; Revised: January $31^{\text {th }}, 2020$; Accepted: January $31^{\text {th }}, 2020$

\begin{abstract}
Background: Radiotherapy is a cancer treatment method using ionizing radiation. The SIB technique is a technique of providing additional radiation together with the administration of primary radiation. At Kensaras Hospital, booster treatment performed simultaneously with the administration of primary radiation or known as SIB is carried out using the IMRT technique or also known as the SIB IMRT technique. whereas according to Susworo, irradiation techniques on breast cancer are not recommended using the IMRT technique, but should use the FIF technique. The purpose of this study was to determine the governance of radiotherapy and the reasons for choosing the SIB technique.

Methods: This type of research is qualitative with a case study approach. Data collection was carried out in December 2018 until May 2019 at Ken Saras Hospital.

Results: The results showed that the SIB technique had several advantages, among others: better radiation conformity and able to minimize OAR doses. This is proven by obtaining doses which mostly meet ICRU standards. While for OAR doses it also meets quantec tolerance standards, except the right lung at a dose of $2000 \mathrm{cGy}$ the volume exceeds $30 \%$, which is equal to $34.55 \%$. But the dosage according to the doctor's consideration is still said to be safe.

Conclusions: The external radiotheraphy procedure including consulting a doctor, taking CT Simulator data, TPS, verification and treatment. Strengths of the SIB technique: Better irradiation conformity, suppressing OAR doses, reducing toxicity to the skin, only requiring one planning and allowing dose calculation in one planning.
\end{abstract}

Keyword: Radiotherapy; SIB; Breast Cancer.

\section{Introduction (Pendahuluan)}

Penyakit kanker merupakan salah satu penyebab kematian utama di seluruh dunia. Berdasarkan data Global Burder Cancer (GLOBOCAN), International Agency for Research on Cancer (IARC), diketahui bahwa pada tahun 2018 terdapat sekitar 18,1 juta kasus baru kanker dan menyebabkan sekitar 9,6 juta kasus kematian. Penyebab kematian tertinggi pada kejadian kanker tebesar adalah kanker paru-paru sebanyak $18,4 \%$, dikuti kanker payudara $11,6 \%$, kanker prostat 9,2\%, kanker kolorektal 6,1\%, kanker lambung 8,2\% dan kanker hati 8,2\% (Bray, 2018)
Berdasarkan Riskesdas (Riset Kesehatan Dasar) Badan Penelitian dan Pengembangan Kesehatan Kementerian Kesehatan (Balitbangkes) Republik Indonesia tahun 2018 didapatkan penderita kanker pada penduduk semua umur di Indonesia sebesar 1,8\%. Beberapa kasus baru penyakit kanker dengan prosentasi yang tinggi, yaitu kanker payudara, kanker prostat, dan kanker paru, sebesar 43,1\%, 30,7\%, dan 23,1\%. Sementara itu, kanker paru dan kanker payudara merupakan penyebab kematian tertinggi akibat kanker.

Teknik SIB digunakan pada kasus kanker payudara post mastectomy, dilakukan dengan pemberian radiasi booster pada lapangan terbatas 
tumor (area bekas operasi/skar operasi) bersamaan dengan dosis primer, tetapi didalam satu lapangan yang sama. Radiasi booster bertujuan untuk membersihkan semua sel-sel tumor ganas yang kemungkinan masih tertinggal pada area skar operasi.

Di RS Ken Saras kabupaten Semarang pemberian radiasi booster dilakukan secara simultan dengan pemberian radiasi primernya atau dikenal dengan istilah Simultaneous Integrated Booster (SIB) dilakukan dengan menggunakan teknik IMRT atau juga dikenal dengan istilah teknik SIB IMRT. Alasan penggunaan teknik SIB, karena teknik ini memiliki banyak kelebihan dibanding apabila pemberian radiasi booster dilakukan dengan teknik nonSIB.

Menurut Katsochi (2017) Teknik SIB terbukti layak diterapkan untuk berbagai macam kanker. Teknik SIB ini sangat dianjurkan digunakan sebagai standar terapi kanker payudara post mastectomy, karena teknik ini dapat mempersingkat waktu perawatan total, meningkatkan kontrol tumor sekaligus menjaga efek samping yang rendah serta dapat mengurangi toksisitas akut pada kulit. Teknik ini dilakukan dengan memberikan dosis radiasi yang berbeda untuk daerah yang berbeda tetapi berada dalam satu lapangan penyinaran yang sama. Sedangkan kelebihan teknik IMRT lainya adalah dapat menghindari struktur jaringan sehat yang menempel pada kanker baik sebagian atau seluruhnya (Haydaroglu, 2012).

Meskipun menurut Susworo (2017), teknik radioterapi pada kanker payudara tidak dianjurkan menggunakan teknik IMRT, karena teknik ini menggunakan berkas sinar yang banyak sehingga dapat menyebabkan peningkatan dosis pada jaringan paru. Teknik radioterapi pada kanker payudara sebaiknya menggunakan teknik Field in Field (FIF).

Kelebihan teknik FIF adalah dapat meminimalkan dosis ke paru-paru, jantung dan payudara kontralateral. Sedangkan kelemahan pada teknik FIF ini adalah dihasilkan dosis hot spot (dosis berlebih) sebesar 7-22\% yang terjadi pada bagian anterior, superior, dan inferior payudara (Haydaroglu, 2012).

Tujuan penelitian ini adalah untuk mengetahui tatalaksana radioterapi dan untuk mengetahui alasan pemilihan teknik Simultaneous Integrated Booster (SIB) pada tatalaksana radioterapi kanker payudara di rumah sakit Ken Saras.

\section{Metode}

Jenis penelitian ini adalah kualitatif dengan pendekatan studi kasus. Pengambilan data dilakukan pada bulan bulan Desember 2018 sampai dengan Mei 2019 di rumah sakit Ken Saras dengan metode obsevasi, wawancara kepada dokter Spesialis Onkologi Radiasi, Fisika Medis, dan Radiografer. Data yang diperolah dari penelitian dianalisis dengan model interaktif, membuat transkip wawancara kemudian direduksi dan diolah dalam bentuk koding terbuka, disajiakan dalam bentuk kuotasi dan

kemudian diambil kesimpulan. Penelitian ini sudah dinyatakan layak etik oleh Komisi Etik Penelitian Kesehatan Health Research Ethics Commitee Poltekkes Kemenkes Semarang yang tertuang dalam Keterangan Layak Etik Description of Ethical Exemption "Ethical Exemption" N0.120/EA/KEPK/2019

\section{Hasil dan Pembahasan}

Tatalaksana Radioterapi Eksterna pada Kanker Payudara dengan Teknik Simultaneous Integrated Booster (SIB) di Unit Radioterapi Instalasi Radiologi Rumah Sakit Ken Saras Kabupaten Semarang dimulai dengan konsultasi dan pemeriksaan dokter. Dokter onkologi radiasi memberikan rujukan untuk dilakukan USG mammae sinistra. Selanjutnya dokter menentukan jenis tindakan radioterapi dan dosis penyinaran sesuai dengan indikasi pasien, kemudian melakukan kontrak waktu untuk perencanaan radioterapi. USG mammae sinistra dilaksanakan pada tanggal 30 Oktober 2018.

Tahapan berikutnya adalah CT Simulator. Dimulai dengan persiapan pasien dan persiapan alat yaitu pesawat CT Simulator serta aksesoris treatment yaitu Base plate, Sandaran thorax abdomen wedge 0 (TA0), Sandaran thorax abdomen wedge 15 (TA15), bantal B3, Arm rest Long (ARL), Knee Support B (KSB), Leg Positioning (LPEC)

Pasien diposisikan supine atau tidur terlentang diatas meja pemeriksaan, dengan kepala yang masuk terlebih dahulu atau head first. Mid sagital plane tubuh pasien berada pada pertengahan meja pemeriksaan dengan kedua lengan tersupport pada arm rest low atau ARL dan kedua tangan memegang alat fiksasi atau Hand Grid Double. Posisi objek harus diatur sebaik mungkin dalam keadaan pasien posisi rileks, badan lurus, kemudian kepala pasien diletakkan pada bantalan kepala, dengan posisi simetris dengan ekstensi normal, 
punggung rileks menempel pada thorax abdomen wedge 0 atau TA0. Berikan skin marker untuk penanda pada bed mammae, scar operasi dan drain operasi (apabila ada).

Atur 3 titik referensi marker radiopaque pada persilangan dari laser midline, lateral kanan dan lateral kiri. 3 titk referensi ini diletakkan pada dinding dada yang akan dijadikan titik referensi untuk iso senter. Gambar titik pertemuan laser menggunakan spidol pada tubuh kemudian letakkan markerpada tiga titik referensi.

Atur sentrasi dengan area scanning batas atas pada setinggi mastoid dan batas bawahnya setinggi suprarenal. Selanjutnya dilakukan CT Scan yang dimulai dari pengambilan gambar scannogram, kemudian dilanjutkan scanning

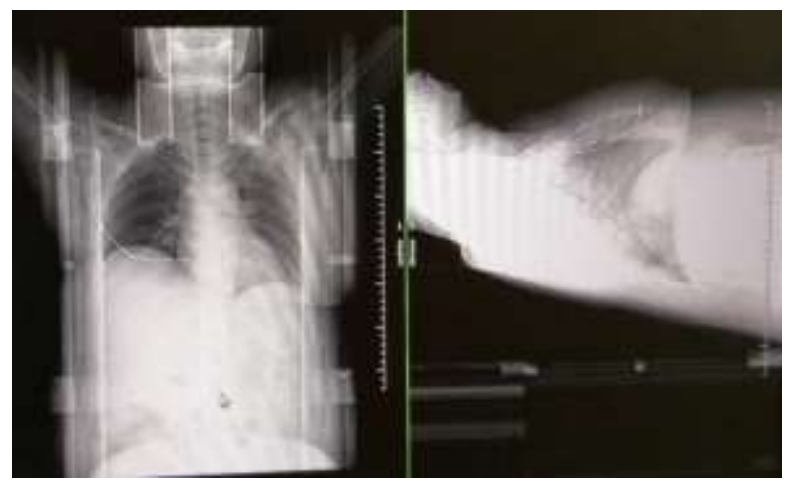

Gambar 1. Scanogram

Hasil scanning diprint dan soft file dikirim ke ruang Treatment Planning System (TPS).

Dokter Spesialis onkologi radiasi melakukan deliniasi atau conturing hasil CT Simulator payudara, untuk memetakan mana yang merupakan daerah target, mana yang merupakan daerah Organ At Risk. Sehingga bisa dipastikan bahwa volume targetnya sudah memadai dan volume Organ At Risk nya sudah ter cover dengan aman.

Dosis yang diberikan terbagi menjadi 3 PTV:

a) PTV mammae primer dengan dosis $30 \mathrm{X}$ $1,75 \mathrm{~Gy}$

b) PTV booster $30 \mathrm{X} 2 \mathrm{~Gy}$

c) PTV supraclavicula 30 X 1,65 Gy

Mengacu Keputusan Mentri Kesehatan (KMK) nomor 1427/MENKES/XII/2006 tentang standar pelayanan radioterapi bahwa kurva Iso dosis yang homogeny, berdasarkan International Commision on Radistion Unit and Measurements (ICRU) 62 yaitu 95\% meliputi PTV dan dosis maksimum (hot spot) maksimum $107 \%$.

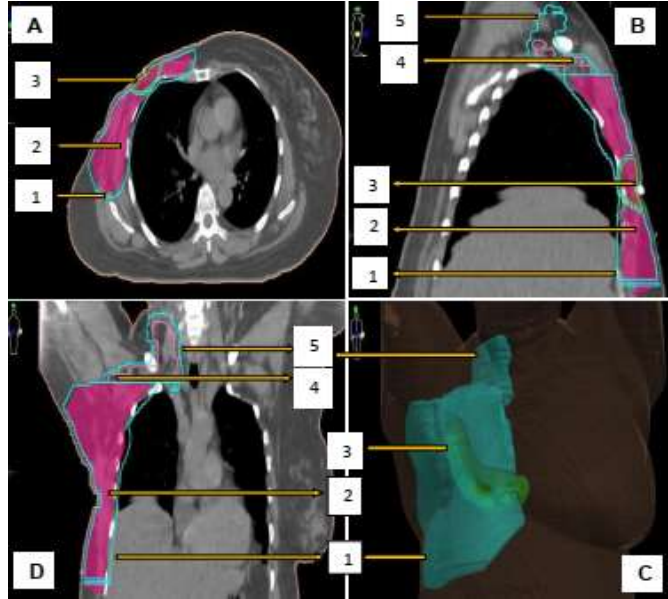

Gambar 2. PTV dan CTV. A.Potongan axial,

B. Potongan sagital, C. Potongan coronal, D. Gambar 3 dimensi, 1. PTV brest primer, 2. CTV brest, 3. PTV booster, 4. CTV Supraclav, 5. PTV Supraclav

Tabel 1. Distribusi Dosis PTV

\begin{tabular}{|l|r|l|l|r|}
\hline \multirow{2}{*}{ PTV } & \multicolumn{2}{|c|}{ DOSIS 95\% } & \multicolumn{2}{c|}{$\begin{array}{c}\text { HOT SPOT } \\
(107 \%)\end{array}$} \\
\cline { 2 - 5 } & $\begin{array}{l}\text { DOSE } \\
(\mathrm{cGy})\end{array}$ & $\begin{array}{l}\text { VOL. } \\
>\end{array} \%$ & $\begin{array}{l}\text { DOSE } \\
(\mathrm{cGy})\end{array}$ & $\begin{array}{r}\text { VOL. } \\
>(\%)\end{array}$ \\
\hline $\begin{array}{l}\text { PTV breast } \\
\text { primer } \\
(52,5 / 30 \mathrm{fx})\end{array}$ & $\begin{array}{r}4987, \\
5\end{array}$ & 92,12 & 5617,5 & 2,73 \\
\hline $\begin{array}{l}\text { PTV booster } \\
(60 / 30 \mathrm{fx})\end{array}$ & 5700 & 98,92 & 6420,0 & 0,42 \\
\hline $\begin{array}{l}\text { PTV } \\
\text { Supraclav } \\
(49,5 / 30 \mathrm{fx})\end{array}$ & $\begin{array}{r}4702, \\
5\end{array}$ & 92,70 & 5296,5 & 0,78 \\
\hline
\end{tabular}

Pada PTV breast primer dosis 4987,5 cGy dan PTV Supraclav dosis 5700 cGy atau dosis 95\% dari dosis PTV, total volume dibawah $95 \%$. Hal ini terjadi karena PTV breast sangat berdekatan dengan PTV booster sehingga apabila volume dinaikkan akan berakibat pada kenaikan dosis hot spot nya. Sedangkan untuk PTV Supraclav volume tersebut untuk menghindari dosis hot spot yang berlebih.

Standar volume dosis hot spot di RS Ken Saras adalah $<2 \%$. Sedangkan volume dosis hot spot PTV breast primer adalah 2,73\%. Hal ini juga diakibatkan karena letak karena PTV breast sangat berdekatan dengan PTV booster. Apabila dosis hot spot PTV breast primer diturunkan lagi maka akan berakibat pada penurunan dosis total PTV breast primer.

Kemudian dilakukan planning oleh fisikawan medis. Planning oleh fisikawan medis ini meliputi pengaturan arah sinar dan penentuan luas lapangan, setelah itu dilanjut ke segmentasi. Dengan menentukan jaringan sehat di 
sekitarnya, target tumor dan organ apa saja yang berpengaruh yang ada di sekitarnya, antara lain paru-paru, jantung, mammae kontra lateral, medulla spinalis, esophagus, trachea, caput humerus serta larynk.

Standar dosis toleransi yang digunakan di RS Ken Saras kabupaten Semarang adalah quantec.

Tabel 2. Perbandingan dosis OAR hasil TPS dengan standar quantec

\begin{tabular}{|c|c|c|}
\hline $\begin{array}{c}\text { ORGAN } \\
\text { AT RISK } \\
\text { (OAR) }\end{array}$ & HASIL TPS & $\begin{array}{l}\text { STANDAR } \\
\text { QUANTEC }\end{array}$ \\
\hline Heart & V25: $1,76 \%$ & $\mathrm{~V} 25<10 \%$ \\
\hline Right lung & $\begin{array}{l}\text { Mean : } 1799,6 \\
\text { cGy } \\
\text { V20 : } 34,55 \%\end{array}$ & $\begin{array}{l}\text { Mean } \leq 20 \\
\text { Gy } \\
\text { V20 } \leq 30 \%\end{array}$ \\
\hline Left lung & $\begin{array}{l}\text { Mean : } 562,1 \text { cGy } \\
\text { V20 : } 0,06 \%\end{array}$ & $\begin{array}{l}\text { Mean } \leq 20 \\
\text { Gy } \\
\text { V20 } \leq 30 \%\end{array}$ \\
\hline $\begin{array}{l}\text { Medula } \\
\text { Spinalis }\end{array}$ & $\begin{array}{l}\text { Dmax }: 2467,5 \\
\text { cGy }\end{array}$ & $\begin{array}{l}\text { Dmax }<50 \\
\text { Gy }\end{array}$ \\
\hline Trachea & V52:0\% & V52<10\% \\
\hline Esophagus & Mean : 702,5 cGy & Mean< $34 \mathrm{~Gy}$ \\
\hline Hepar & $\begin{array}{ll}\begin{array}{l}\text { Mean } \\
\text { cGy }\end{array} & 1341,8 \\
\end{array}$ & Mean $<28$ Gy \\
\hline Larynk & $\begin{array}{l}\text { Dmax }: 4684,8 \\
\text { cGy } \\
\text { Mean }: 333,5 \text { cGy }\end{array}$ & $\begin{array}{l}\text { Dmax }<66 \\
\text { Gy } \\
\text { Mean< } 40 \text { Gy }\end{array}$ \\
\hline
\end{tabular}

Secara umum dosis yang diterima OAR nya masih dibawah standar toleransi quantec, tetapi untuk paru kanan pada dosis 2000 cGy yang diterima mebihi volume $30 \%$, yaitu sebesar $34,55 \%$. Tetapi dosis tersebut menurut pertimbangan dokter masih dikatakan aman.

Menurut Soehartati (2017) Left Anterior Descending Coronary Artery atau arteri koroner dietapkan termasuk dosis OAR dalam kanker payudara, tetapi di rumah sakit Ken Saras memperhitungkan secara khusus sebagai dosis OAR. Hal ini dikarenakan rumah sakit Ken Saras belum menganut hal tersebut sebagai protokol. RS Ken Saras menetapkan jantung secara keseluruhan sebagai OAR, sehingga arteri coroner sudah tercakup dalam penghitungan dosis toleransinya.

Penentuan dosis toleransi OAR di RS Ken Saras menggunakan standar quantec, dimana payudara kontra lateral dan caput humerus belum ditetapkan limitasi dosis toleransinya. Rumah sakit Ken Saras menetapkan kedua organ ini sebagai OAR, dikarenakan kedua organ ini berdekatan dengan area radiasi dan sangat beresiko terhadap efek samping penyinaran yang dilakukan. Dosis toleransi payudara kontra lateral ditetapkan oleh dokter onkologi radiasi diharapkan mean < $500 \mathrm{cGy}$ dan caput humerus: max dose $<4.800 \mathrm{cGy}$. Hasil pengitungan TPS didapatkan pada payudara kontra lateral mean sebesar 357,7 cGy dan caput humerus: max dose : 3.339,7 cGy.

Setelah selesai conturing dan planning di TPS, selanjutnya data dikirim dari komputer TPS ke komputer mosaic untuk diolah. Data yang dihasilkan di TPS belum tertata dengan sistematis kemudian dilakukan pengaturan urutan lapangan penyinaran sehingga akhir lapangan penyinaran berada pada titik 0 (nol) atau mendekati titik 0 tersebut. Hal ini bertujuan untuk efektifitas pergerakan gantrinya.

Tahapan selanjutnya adalah verifikasi lapangan penyinaran. Persiapan alat, aksesoris sama seperti pada waktu CT Simulator. Aksesoris lain yang digunkan adalah reticle. Pasien diposisikan sama seperti pada saat CT Simulator. Lakukan pengambilan gambar EPID portal Antero Posterior dan Lateral. Di instalasi radioterapi rumah sakit Ken Saras sebelum dilakukan penyinaran, lapangan penyinaran yang sudah di planning di TPS akan diverifikasi terlebih dahulu. Setelah dilihat dan disetujui oleh dokter kemudian dilakukan penyinaran radiasi. Verifikasi lapangan penyinaran dilakukan sebelum penyinaran pertama. Disamping itu, verifikasi lapangan penyinaran juga dilakukan pada fraksi kelima apabila pada fraksi 1,2 dan 3 pasien mengalami pergerakan iso senter atau perubahan bentuk tubuh. Batas toleransi pergeseran yang ditetapkan di rumah sakit Ken Saras adalah < $2 \mathrm{~mm}$. Sedangkan petugas yang melakukan verifikasi adalah radiografer.

Menurut Hoskin (2007) verifikasi radioterapi adalah proses untuk memastikan bahwa volume tumor yang diradiasi adalah sama seperti yang direncanakan. Tujuan verifikasi adalah untuk memastikan bahwa akurasi geometris dari radiasi yang diberikan masih dalam batas-batas yang diperbolehkan dalam rencana penyinaran. Verifikasi yang dilakukan pada kasus ini dengan menggunakan Electronic Portal Image Device (EPID), jika hasil verifikasi sudah benar maka dilakukan penyinaran. Sebelum dilakukan penyinaran, lapangan penyinaran yang sudah dihitung di TPS akan diverifikasi terlebih dahulu. Verifikasi dilakukan dengan pengambilan gambar AP dan lateral. Dilakukan selama 3 hari pertama pengobatan dan durasi mingguan sesudahnya. Biasanya toleransi $\pm 3 \mathrm{~mm}$ dapat diterima, meskipun harus lebih ketat apabila OAR sangat berdekatan dengan volume target. 
Menurut KPKN Kemenkes (2017), verifikasi untuk untuk 3D-CRT dan FIF harus dilakukan untuk 3 fraksi pertama dengan EPID, diikuti dengan setiap 5 fraksi. Setelah dilihat dan disetujui oleh dokter kemudian dilakukan penyinaran radiasi.

Keputusan Menteri Kesehatan (KMK) nomor 1427/MENKES/XII/2006 tentang standar pelayanan radioterapi, menyatakan bahwa ketepatan lapangan radisi harus diverifikasi dengan alat/fasilitas yang dianggap cukup memadai untuk melakukan tindakan verifikasi tersebut. Verifikasi dilakukan dengan pesawat radiasi minimal 1 (satu) kali setiap penentuan lapangan penyinaran baru. Dengan toleransi ketidak tepatan tidak lebih dari 5 $\mathrm{mm}$. Sedangkan pada indikator klinik yang bertujuan untuk meningkatkan mutu pelayananan, ditetapkan bahwa deviasi harus lebih kecil dari 2 $\mathrm{mm}$. Pada verifikasi atau set-up pertama kali apabila terapi bersifat komplek dianjurkan kehadiran ketiga profesi, yaitu dokter onkologi radiasi, fisikawan medis dan radiografer

Sehari setelah dilakukan verifikasi lapangan penyinaran, tepatnya pada tanggal 8 November tahun 2018 dilakukan penyinaran/ treatment yang pertama kali. Prosedurnya yaitu Petugas memanggil nama pasien, mencocokkan identitas, kemudian pasien dipersilahkan masuk ke ruang penyinaran. Pasien diposisikan sama seperti pada saat CT Simulator. Tutup pintu ruang penyinaran. Pilih nama pasien pada jadwal penyinaran hari tersebut. Lakukan penyinaran. Pelaksanaan treatment pada Tatalaksana Radioterapi Eksterna pada Kanker Payudara dengan Teknik Simultaneous Integrated Booster (SIB) di Instalasi Radiologi Unit Radioterapi Rumah Sakit Ken Saras Kabupaten Semarang menggunakan pesawat LINAC yang mempunyai Multy Leaf Collimator (MLC), dengan menggunakan energy foton sebesar $6 \mathrm{MeV}$. Spesifikasi LINAC yang dimiliki RS Ken Saras mendukung untuk pelaksanaan teknik IMRT, sehingga teknik SIB ini bisa diterapkan di RS Ken Saras. Sistem pelayanan radioterapi di RS Ken Saras semuanya juga terkoneksi menggunakan sistem komputer, sehingga tidak dimungkinkan adanya kesalahan dalam pelaksanaan treatment.

Menurut Darmawati (2012), salah satu alat teleterapi adalah pesawat pemercepat elektron (Linear Accelerator/LINAC). Sejak Tahun 1970-an penggunaan Linear Accelerator energi tinggi mempunyai multienergi berkas elektron dan foton, yaitu pada energi elektron untuk keperluan radioterapi adalah berkisar 4-22 $\mathrm{MeV}$ dan untuk energi foton adalah 6-8 MV. Pesawat LINAC telah digunakan untuk terapi berbagai jenis tumor dan dirancang untuk menghasilkan multi energi berkas foton maupun elektron, sehingga alat ini dapat digunakan untuk berbagai kedalaman letak kanker.

Alasan digunakanya teknik Simultaneous

Integrated Booster (SIB) di RS Ken Saras

kabupaten semarang ini antara lain karena: untuk memperoleh distribusi dosis yang lebih akurat baik pada area primer dan pada area OAR atau komformitas yang lebih bagus, untuk menekan dosis OAR, cukup hanya menggunakan 1 planning dan dapat menekan jumlah fraksi penyinaran yang dilakukan.

\section{Simpulan}

Tatalaksana Radioterapi Eksterna pada kanker Payudara dengan Teknik Simultaneous Integrated Booster (SIB) di Unit Radioterapi Instalasi Radiologi RS Ken Saras Kabupaten Semarang meliputi konsultasi dokter, CT Simulator, Treatment Planning System, verifikasi dan treatment atau penyinaran.

Hasil dari Teknik SIB ini adalah Konformitas penyinaran lebih bagus, dapat menekan dosis yang diterima Organ At Risk (OAR), dapat mengurangi toksisitas pada kulit, hanya membutuhkan 1 (satu) planning, memungkinkan dilakukannya rekalkulasi dosis dalam 1 (satu) planning meliputi 3 (tiga) area dosis sudah bisa tercapai semua.

\section{Daftar Pustaka}

Balitbangkes, Kemenkes RI, 2018, Hasil utama Riset Kesehatan Dasar (RISKESDAS) 2018

Beyzadeoglu Murat, Gokhan Ozyigit, Cuneyt Ebruli, 2010, Basic Rdiation Oncology, Springer Heidekberg Dordrecht London New York.

Bray Freddie, BSc, MSc, PhD, Ferlay Jacques, ME, Soerjamataram Isabelle, MD, MSc, PhD, Siegel Rebecca L, MPH, Torre Lindsey A, MSPH, Jemal Ahmedin, PhD, DVM, 2018, Global Cancer Statistics 2018: GLOBOCON Estimates of Incidence and Mortality Worldwide for 36 Cancers in 185 Countries, Atlanta

Darmawati, Suharni, 2012, Implementasi Linear Accelerator Penanganan Kasus Kanker. http://digilib.batan.go.id/ppin/katalog/file/14111349-2012-036

Depkes RI, 2006. Keputusan Mentri Kesehatan RI No. 1427/Menkes/SK/XII/2006, tentang Standar Pelayanan Radioterapi di Rumah Sakit.

Haydaroglu Ayfer, Ozyigit gokhan, 2012, Principles and Practice of modern radiotherapy Techniques in breast Cancer, Ankara, Turkey.

Hoskin Peter, 2012. Radiotherapy In Practice, External BeamTherapy, Second edition, Oxford. 
Katsochi Despina, 2017, Radiation Therapy With a Simultaneous Integrated Boost

Komite Penanggulangan Kanker Nasional (KPKN), 2017, Panduan Penatalaksanaan Kanker Payudara, Kementrian Kesehatan RI.

Soehartati A. Gondhowiardjo Prof. Dr.dr, 2017, Pedoman Praktis, Deliniasi Volume Target Terapi Radiasi, Fakultas Kedokteran Universitas Indonesia, Jakarta.

Susworo. R, 2017, Radioterapi : Dasar-Dasar Radioterapi, Tatalaksana Radioterapi Penyakit Kanker, Jakarta : UI-Press 